\title{
Processos Clínicos em Núcleos de Apoio à Saúde da Família / NASF: Estágio Supervisionado
}

\author{
Clinical Processes In Family Health Care Center: \\ Supervised Training Course
}

Procesos Clínicos En Núcleos De Apoyo A La Salud De La Familia (NASF): Pasantía Supervisionada
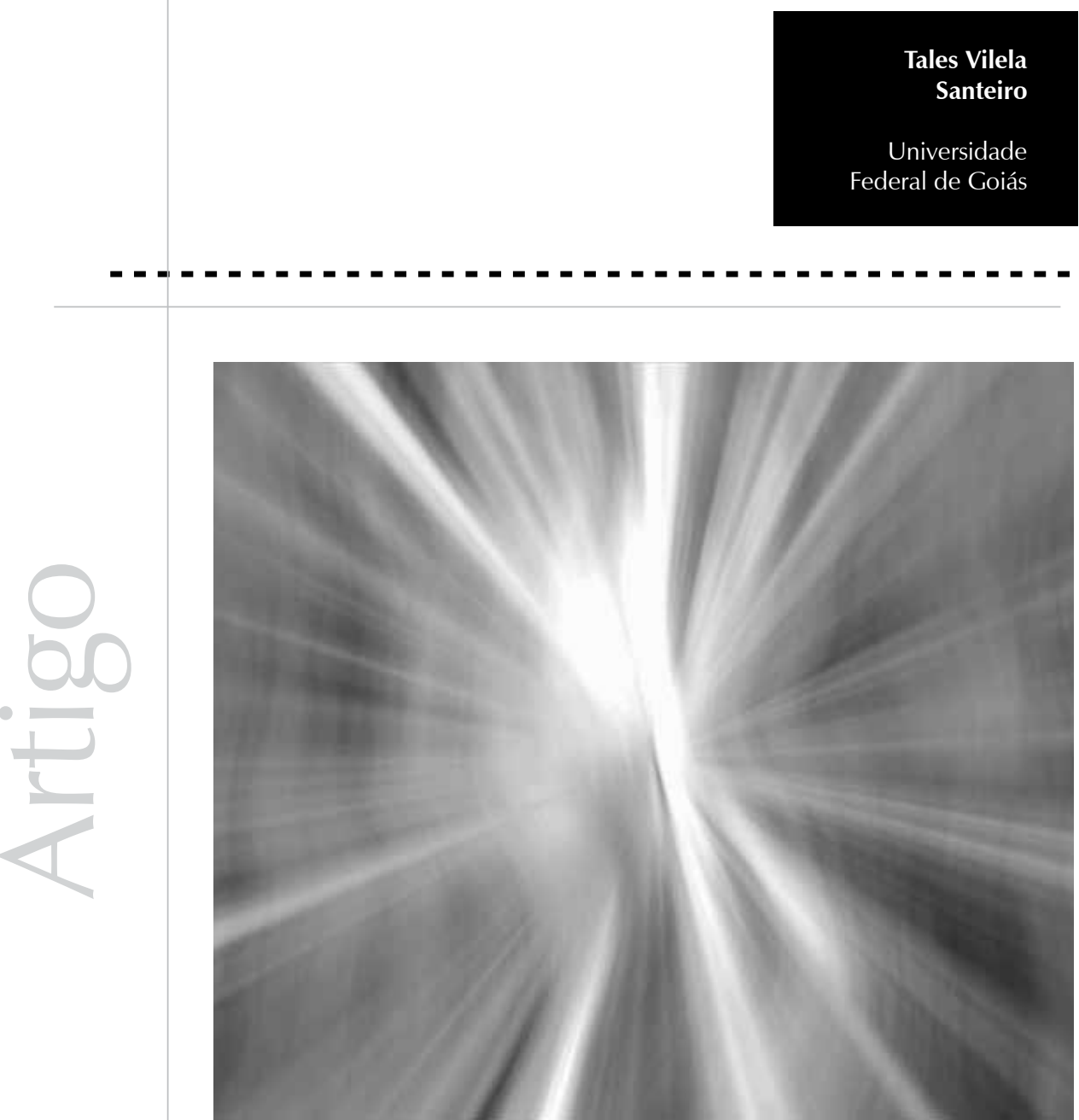
Resumo: Os diálogos entre a Psicologia e a saúde pública têm se estreitado nos últimos anos, visando à consolidação da profissão em seus compromissos com a realidade brasileira. Este artigo objetiva discutir o papel da Psicologia clínica integrada a Núcleos de Apoio à Saúde da Família (NASF), equipamentos do Sistema Único de Saúde. As discussões enfocadas resultam de estágios desenvolvidos por estudantes de universidade pública federal, de cidade de pequeno porte do interior do Centro-Oeste. As atividades ocorrem em cinco NASF e perfazem, por semestre, 16 semanas de estudos teóricos e de intervenção supervisionada, em andamento desde 2011. Na realidade retratada, atividades de ensino e aprendizado em Psicologia clínica em suas interfaces com a saúde pública têm ocorrido entre distintas demandas: as dos usuários, compreendidos como singulares e representantes do entorno social, e as da formação em Psicologia, comprimidas entre imperativos vinculados às políticas públicas de ensino superior e de saúde pública. Há ponderações sobre o custo emocional que se coloca aos estagiários em busca de identidade profissional nesse contexto. Articular distintas necessidades permanece como desafio a ser vivido e constantemente refletido por profissionais e estudantes de Psicologia clínica.

Palavras-chave: Formação do psicólogo. Intervenção psicossocial. Saúde mental. Saúde pública.

Abstract: The connection between psychology and public health has become narrowed in recent years, aiming at the consolidation of the profession in its commitments to the Brazilian reality. This article discusses the role of the integration of clinical psychology to Family Health Care Centers (NASFs), equipments of the Brazilian Unified Health System. Focused discussions result from supervised training courses developed by students from a public university in a small town in the interior of the Midwest. The activities take place on 5 NASFs and account for 16 weeks of theoretical and supervised intervention per semester, which have been ongoing since 2011. In the reality portrayed, teaching and learning in clinical psychology interfaced with public health have occurred between different demands: the users', understood as individuals and social environment representatives, and those of training in Psychology, compressed into imperatives linked to public policies on higher education and public health. There are considerations about the emotional cost that arises for the trainees who seek professional identity in this context. Articulating distinct needs remains a challenge to be faced and constantly reflected by professionals and clinical psychology students. Keywords: Psychologist education. Psychosocial intervention. Mental health. Public health.

Resumen: Los diálogos entre la Psicología y la salud pública se han estrechado en los últimos años, visando la consolidación de la profesión en sus compromisos con la realidad brasileña. Este artículo tiene el objetivo de discutir el papel de la Psicología clínica integrada a Núcleos de Apoyo a la Salud de la Familia (NASF), equipos del Sistema Único de Salud. Las discusiones enfocadas resultan de pasantías desarrolladas por estudiantes de universidades públicas federales, de ciudades de pequeño porte del interior del Centro Oeste. Las actividades ocurren en cinco NASF y completan, por semestre, 16 semanas de estudios teóricos y de intervención supervisada, en trámite desde 2011. En la realidad retratada, actividades de enseñanza y aprendizaje en Psicología clínica en sus interfaces con la salud pública han ocurrido entre distintas demandas: las de los usuarios, comprendidos como singulares y representantes del entorno social, y las de la formación en Psicología, comprimidas entre imperativos vinculados a las políticas públicas de enseñanza superior y de salud pública. Hay ponderaciones sobre el costo emocional que se les impone a los practicantes en busca de identidad profesional en ese contexto. Articular distintas necesidades permanece como un desafío a ser vivido y constantemente reflexionado por profesionales y estudiantes de Psicología clínica.

Palabras clave: Formación del psicólogo. Intervención psicosocial. Salud mental. Salud pública.

\section{NASF e Psicologia: encontro recente}

Os diálogos entre a Psicologia e a saúde pública têm se estreitado nos últimos anos. Esforços têm visado à consolidação da profissão em seus compromissos com a realidade brasileira e com uma concepção ampliada de atuação do psicólogo, e também do psicólogo que se ocupa dos chamados "processos clínicos" (Ministério da Educação, 2011). Um dos modos de ilustrarmos esse estado de coisas é a inserção do psicólogo no âmbito das Estratégias de Saúde da Família/ESF e, mais especificamente desde 2008, como um dos profissionais que compõem o Núcleo de Apoio à Saúde da Família (NASF). 
Colóquios sobre essa inclusão do psicólogo têm sido correntes e têm produzido contribuições que antecedem o estabelecimento dos NASF (Costa \& Brandão, 2005; Lancetti, 2000; Moreira, Romagnoli, \& Neves, 2007; Spink, 2006). Mais recentemente, eles permanecem em foco, seja para traçar experiências e relatar pesquisas, seja para elaborar e compartilhar os potenciais e as limitações que se colocam aos profissionais (Amaral, Gonçalves, \& Serpa, 2012; Andrade et al., 2012; Conselho Federal de Psicologia, 2009; Lima, 2005; Nepomuceno \& Brandão, 2011; Neumann, Cardoso, \& Oliveira, 2011).

Isso ressalta e justifica a necessidade perene de diálogos entre práticos e acadêmicos. As reflexões que propomos seguem linhas semelhantes às trazidas por essas contribuições e particularmente por aquelas inspiradas pela Psicologia clínica (Ferreira Neto, 2008; Lisboa, Santos, Bassoli, Paiva, \& Fernandes, 2011; Pombo-de-Barros \& Marsden, 2008; Sousa \& Cury, 2009; Sundfeld, 2010).

Para esclarecimento inicial ao leitor que desconhece o vocabulário das Diretrizes Curriculares Nacionais (Ministério da Educação, 2011), processos clínicos são uma das possibilidades de ênfases curriculares a serem praticadas em projetos políticopedagógicos de cursos (PPC) de Psicologia. Esses processos designam um conjunto de competências de que o estudante precisa se apropriar, ao longo de sua formação, para atuar, “(...) de forma ética e coerente com referenciais teóricos, valendo-se de processos psicodiagnósticos, de aconselhamento, psicoterapia e outras estratégias clínicas, frente a questões e demandas de ordem psicológica apresentadas por indivíduos ou grupos em distintos contextos." (2011, p.4).
Essas características são relevantes e devem ser mantidas em mente daqui em diante, porque o PPC do curso ao qual estamos afiliados adota essa ênfase e contempla frentes de estágios básicos e específicos em processos clínicos.

Em continuidade à contextualização dos NASF, com a implantação da Política Nacional de Atenção Básica, ocorrida desde 2006, eles incorporam-se a ela no intuito de revisar e de atualizar toda a regulamentação sobre saúde em vigor até então e expressam a crescente valorização da Atenção Primária e a consolidação da Saúde da Família, como estratégia nacional, em prol do fortalecimento do Sistema Único de Saúde/ SUS (Nunan, 2009).

A ESF, vertente brasileira da Atenção Primária à Saúde, caracteriza-se como a porta de entrada prioritária do SUS, um sistema de saúde governamental fundado no direito à saúde, na equidade do cuidado e, além disso, hierarquizado e regionalizado. Ela pretende provocar um importante movimento de reorientação do modelo de atenção à saúde no Brasil (Ministério da Saúde, 2009).

O NASF é composto de nove áreas estratégicas: 1) saúde da criança/do adolescente e do jovem, 2) saúde mental, 3) reabilitação/saúde integral da pessoa idosa, 4) alimentação e nutrição, 5) serviço social, 6) saúde da mulher, 7) assistência farmacêutica, 8) atividade física/práticas corporais e 9) práticas integrativas e complementares (Ministério da Saúde, 2009).

Observamos, a partir das enumerações feitas, que o campo de atuação no NASF fica em aberto ao profissional da Psicologia, em praticamente todas as nove áreas e, em especial, nas seis primeiras. Isso ocorre na medida em que se entende como 
primordial o trabalho multiprofissional e interdisciplinar, quiçá o transdisciplinar (Galvan, 2007), como provocação cotidiana e alvo de constantes preocupações no modelo de saúde em pauta, de modo que a diversidade profissional seja considerada. Afinal, “(...) podemos lembrar o fato de que não é possível a nenhum trabalhador em saúde esquivar-se de lidar em alguma medida com os afetos nas relações terapêuticas, por mais que se trate de um tema específico de psicólogos e psiquiatras" (Ministério da Saúde, 2009, p.14), ou ainda: "essa proposta (transdisciplinar) deve ser embasada no respeito mútuo e ter como meta a intervenção nessa realidade que sempre se localiza em certo lugar além de qualquer ótica estabelecida por qualquer ciência" (Romagnoli, 2006, p.7).

O Ministério da Saúde/MS (2009) ressalta que não somente o psicólogo mas também as equipes do NASF têm, a rigor, dois tipos de responsabilidades fundamentais: sobre a população e sobre a ESF, isto é, o desempenho do profissional é avaliado tanto por indicadores de que sua atuação resulta para a população quanto por aqueles de resultado da sua ação na equipe. Essa característica acentua as necessidades da ocorrência de trabalhos colaborativos entre os atores desse cenário, já que haveria implicações diretas entre essa condição de trabalho grupal e as avaliações das responsabilidades de toda a equipe.

Ao contemplarmos a amplitude desse cenário, as responsabilidades inerentes a ele são inúmeras. O psicólogo que se integra ao NASF, e também o estagiário de processos clínicos, vê-se comprimido entre as necessidades dos usuários, compreendidos como singulares e representantes do entorno social (Nasciutti, 1996), e as de formação em
Psicologia, comprimidas entre imperativos vinculados às políticas públicas de ensino superior (Ministério da Educação, 2011) e de saúde pública (SUS).

O papel dos supervisores de estágios é entendido como fundamental nessa inserção do estudante de Psicologia clínica e tem como objetivo básico apoiá-lo, do ponto de vista teórico-técnico, diante dos múltiplos desafios encontrados. Entendemos essa função como essencial à manutenção emocional e profissional do estagiário, que se posta nesse jogo de forças que têm sido descritas como resultantes da convergência de demandas institucionais, políticas e dos sujeitos que as integram, nas mais diversas facetas e momentos. As atitudes clínicas são estabelecidas, portanto, em trocas de experiências entre estudantes e supervisores. Debates como esses serão retomados daqui em diante.

Nesse sentido, trazemos algumas reflexões sobre os desafios enfrentados por supervisores clínicos e por estagiários de Psicologia inseridos em Núcleos de Apoio à Saúde da Família, situados em cidade de pequeno porte, no interior do Centro-Oeste. Destacamos como a prática desses personagens, aqui entendidos como estudantes de Psicologia clínica, encontrase permeada e condicionada por aspectos de natureza política e social. Também enfatizamos como esses condicionantes interferem na natureza das práticas e como impactam as experiências pessoais dos que ali se situam. Em relação aos professores supervisores, chamamos a atenção para a necessidade que têm de revisar epistemológica e teoricamente a Psicologia clínica, em face das demandas e da realidade que as novas políticas públicas ensejam. 


\section{Ações de saúde mental articuladas por psicólogos: profissão e ciência}

Os modos de olhar os fenômenos humanos e seus processos de adoecimento e de saúde convergem em alguns momentos; em outros, parecem distantes, tal como apartados em proporções continentais uns em relação aos outros. A saúde pública e a Universidade compreendem dois desses olhares que buscam, em meio às divergências, uma aproximação sucessiva e progressiva no modo de compreender o processo saúde-doença. O modo de fazer o encurtamento dessas distâncias, porém, ainda é incipiente. Há divergências entre práticas e discursos, o que gera contrastes entre os trabalhos do profissional situado no NASF, com o do formador de psicólogos e o dos estagiários. Nesse bojo, atividades de estágio caracterizam-se como uma forma de buscar proximidade entre discursos acadêmicos e da profissão Psicologia com aqueles decorrentes das práticas ocorridas na saúde pública.

Como preveem as Diretrizes Curriculares Nacionais (Ministério da Educação), nos cursos de graduação em Psicologia, os estágios precisam ser "supervisionados por membros do corpo docente da instituição formadora" (2011, p.7). O supervisor busca consolidar as experiências de aprendizado do estudante que vai ao campo profissional cumprir essa etapa do processo formativo. O encontro entre as frentes da Academia e da prática podem, assim, buscar a convergência necessária em que se baseiam os discursos governamentais direcionados ao terreno da saúde e da educação, e têm na figura dos supervisores um dos eixos centrais no processo formativo.
O adentrar da Psicologia no NASF desenhase, desse modo, como um fenômeno recente para todos: para aquele que o faz como profissional (supervisor direto), para o supervisor de estágios acadêmicos (supervisor indireto) e para os estagiários. Embora haja diretrizes governamentais relativamente claras sobre o modo como o profissional da Psicologia deveria operar no complexo sistema de saúde pública brasileira (Ministério da Saúde, s.d., 2009), é sabido que essa colocação exige tempo para a maturação de suas potências. E, nesse momento, há menção aos psicólogos que se encontram para estudar Psicologia clínica no NASF, como um grupo de profissionais, formados e em processo de formação, interessados em promover saúde e auxílio psicoterapêutico àqueles que sofrem.

Esse tempo de maturação ao qual nos referimos é necessário basicamente por duas razões: 1) pelo frescor do momento histórico no qual essas políticas públicas têm sido implementadas e 2) pelo traçado da formação acadêmica de psicólogos nas instituições de ensino superior brasileiras, que, em seus 50 anos de regulamentação, comemorados em 2012, permanece criticada pelo distanciamento no que tange às realidades da saúde pública do País. Os supervisores e os estagiários aventuram-se em um campo onde o desconhecido é marca habitual, e todos eles propõem-se a diálogos em busca do aprendizado sobre a realidade dos usuários e do próprio SUS.

Estudar e viver Psicologia clínica constitui um movimento delicado, ainda em construção e adequação. Quem trabalha no intercâmbio entre educação e saúde pode observar demandas das políticas públicas para que projetos político-pedagógicos sejam avaliados para a solução de problemáticas antigas da 
saúde pública brasileira. Parece haver expectativas de que a Universidade consiga, enfim, contemplar falhas historicamente constituídas. Mesmo que a Academia tenha compromissos sociais inquestionáveis, ela não tem como ser a grande responsável por suplantar problemáticas tão arraigadas, sem que, com isso, corra o risco de perder-se de suas responsabilidades pedagógicas.

Essa delicadeza precisa ser considerada principalmente quando se pensa no estagiário como um sujeito atuante em terreno que comporta inúmeros desafios: aqueles derivados da cobrança de capacidade de atuação e do próprio processo de aprendizagem. O estudante precisa, portanto, responder a exigências externas e internas. As externas originamse da instituição de ensino superior (IES) e do NASF onde está inserido. As solicitações internas, além das postas pelo processo de aprender, corresponderiam ao momento específico de desenvolvimento pessoal e acadêmico do estagiário, e a maneira pela qual ele lida internamente com cobranças pode potencializar suas angústias. De todo modo, o lugar do aprendiz está determinado por escolhas que precisam ser feitas em pouco tempo: o estágio precisa iniciar, desenvolver-se e encerrar-se em um semestre letivo.

\section{Psicologia clínica e formação profissional por meio de estágio}

É importante salientarmos que o encontro da Psicologia com a saúde pública ocorre em um momento em que a saúde mental tem sido foco de atenção, não somente em esferas locais. Veem-se organizações internacionais mobilizando-se em torno de novas concepções e novas esperanças sobre a saúde mental (Organização Mundial da Saúde, 2001), o que indica serem universais as dificuldades e os desafios apresentados nesse campo.

Nesse panorama, temos gerado diversos questionamentos e inquietações no trabalho de supervisão de estágio. Eles são entendidos como necessários e, neste artigo, contemplaremos alguns deles: há lugar para a Psicologia clínica? Quais os papéis dos supervisores e, por conseguinte, os dos serviços-escola de Psicologia? Qual o custo emocional que se coloca aos estagiários em busca de identidade profissional, no entremeio de pressões governamentais, institucionais e pessoais?

Perguntas como essas têm sido presentes e insistentes, quando da integração de estagiários de universidade pública federal aos NASF descritos. As atividades práticas e de supervisão provocadoras das discussões resultaram de estágios desenvolvidos em cinco territórios. Elas perfazem, por semestre letivo, 16 semanas de estudos teóricos e de intervenção supervisionada e estão em andamento desde 2011.

Supervisor direto é o termo que designa o profissional que se responsabiliza diretamente pelo estagiário, inclusive porque toda e qualquer documentação decorrente dos trabalhos do estudante precisa ser endossada por ele, que realiza acompanhamentos presenciais e auxilia o estagiário a compreender a rotina da instituição, o que inclui preencher documentos que precisam ser encaminhados semanalmente à Secretaria de Saúde do Município e também discutir casos atendidos, quando a agenda desse profissional, com frequência superlotada, permite. Em situações necessárias, os usuários são encaminhados a outros profissionais que 
constituem a equipe daquela ESF, ou, em último caso, a equipamentos de saúde disponíveis, para atendimento em nível de atenção secundário ou terciário.

No caso em tela, o supervisor indireto é o professor vinculado à IES, porque o acompanhamento oferecido ao estudante não é presencial, não ocorre no campo onde o estágio se desenvolve. A despeito de não realizarmos acompanhamento presencial nos NASF, nós o fazemos semanalmente, nas dependências do Serviço-Escola de Psicologia. Nesse momento de supervisão, reflexões teórico-técnicas sobre o manejo clínico são feitas com os grupos de estagiários.

Logo, o que define se um supervisor desempenha função direta ou indireta é se ele concede o campo de estágio, podendo, nesses termos, haver coincidência entre supervisão direta e indireta, o que, todavia, não ocorre no nosso caso. Ambos os supervisores são, portanto, responsáveis pelo desenvolvimento profissional do estagiário. Essas observações são feitas para que o leitor não familiarizado com as rotinas do NASF visualize como ocorre a inserção dos estagiários de Psicologia nesse contexto. As responsabilidades atribuídas a eles são indistintas em relação àquelas recebidas pelo profissional que os acolhe (supervisor direto). Elas incluem atendimento a todos os tipos de casos encaminhados por terceiros, ou daqueles que buscam auxílio de modo espontâneo. Observamos que, no Município estudado, os atendimentos têm ocorrido basicamente em caráter ambulatorial, sendo que os usuários se dirigem aos NASF e agendam seus atendimentos com as respectivas secretárias. Se há disponibilidade horária por parte do estagiário, os usuários são encaixados e atendidos sem espera.
O tipo de intervenção praticada é sujeito às demandas apresentadas pelo território no qual o NASF se insere, usualmente formuladas por meio dos agentes de saúde, mas, como é sabido, isso também ocorre por ação de outros profissionais da ESF (por exemplo, Lancetti, 2011). Nesse sentido, as intervenções praticadas pelos estagiários têm acontecido de duas formas básicas: ou situadas nas dependências dos próprios NASF, em um atendimento mais aproximado ao do modelo tradicional de psicólogo clínico, e/ou nas residências dos usuários.

Os atendimentos, tanto aqueles ocorridos em ambulatório quanto os residenciais, têm sido pautados por condutas que são inspiradas em propostas técnicas advindas de intervenções focais e breves. As formulações clínicas são embasadas mais em atitudes de empatia e flexibilidade, com o objetivo de fortalecimento de eficácia adaptativa do sujeito em situação de crise do que em uma técnica (Yoshida \& Enéas, 2007). Entretanto, esse tipo de detalhamento carece de outros espaços e momentos para ser devidamente considerado.

\section{Discernimento profissional e saúde mental}

Embora o exercício que se propõe a discutir a inserção da Psicologia clínica na saúde pública não denote novidade para muitos leitores familiarizados com as questões que a permeia, justamente por ser recente, precisa ser incansavelmente formulado. Em assim sendo, não duvidamos de que haja lugar para a Psicologia clínica no NASF, em especial quando entendemos que ela é constituída, acima de tudo, por profissionais motivados a auxiliar pessoas em situações de sofrimento, e, igualmente, quando ponderamos que um psicólogo clínico se define mais pelas atitudes e ferramentas teórico-técnicas que 
utiliza do que pelo campo de atuação no qual se firma como trabalhador.

Um psicólogo clínico se delimita, além disso, pela direção de suas escutas e intervenções, como um cuidador que usufrui e co-ordena as relações humanas, como referência nesse mesmo terreno relacional: ele é quem, no Brasil, dedica e/ ou dedicou, de modo diferenciado, anos de sua vida formando-se para compreender os fenômenos comportamentais e psíquicos e os processos clínicos.

Por razões como as apresentadas, estratégias de ensino que fomentem e expandam atitudes clínicas do estagiário são fundamentais para sua manutenção nesse território. Ao mesmo tempo, os conhecimentos necessários à conquista dessas atitudes prescindem de um lugar físico. Um NASF é espaço de intervenção, tanto quanto o seria um consultório particular, no sentido de que ali podem ser operadas as ações de cuidado e atenção à saúde das pessoas.

Como dito, a formação em Psicologia clínica confere ao profissional uma especialidade não encontrada em outros perfis acadêmicos e reveste-o de uma potência a ser considerada, desde que esteja claro que não se pretende defendê-la como um modo de psicologizar a sociedade (Dimenstein, 1998). Ao contrário, pretendemos considerá-la como abertamente distante das práticas de cunho elitista e nas quais um saber acadêmico se sobrepõe e suplanta o do outro, ameaçando-o em sua singularidade. Nessa direção, o estudante não pode ansiar, nem agir, como se o espaço do NASF fosse um consultório deslocado da prática privada.
Esse nível de debate tem sido considerado, ao longo dos últimos tempos, por diversos autores concernentes ao campo das psicoterapias breves (Simon, 1981; Yoshida, 1993; Lipp \& Yoshida, 2012). Contudo, tal como assinalado há pouco, neste texto, ele será, por opção e por ora, suspenso. Vale dizer, no entanto, que observamos aproximações entre o que se entende por intervenções usualmente classificadas como pertencentes à promoção de saúde e as chamadas psicoterapias breves, sem com isso defendermos um modelo curativo de Psicologia clínica no NASF. Para nós, um psicólogo clínico adequado não seria aquele apto a remedar modelos teórico-técnicos prontos e importados, e sim, o disponível para ouvir e aprender sobre a realidade daqueles com os quais desenvolve seus trabalhos.

Nesse interjogo, as questões de teor emocional surgidas no trabalho do estudante precisam estar diferenciadas de outras necessidades que não pertencem nem ao usuário, nem ao estagiário. Nesse trabalho de diferenciação, a presença de um supervisor clínico fica estabelecida como provedor de suporte psíquico, para além das questões exclusivamente pedagógicas, acima assinaladas como apoio teórico-técnico.

A saúde pública exige, também, do supervisor e do estagiário, disponibilidade para o enfrentamento de peculiaridades políticas e de seus emaranhados. A saúde mental do estudante e a postura profissional decorrente podem ser comprometidas ao se experimentar graus de impotência diante de limites - ou impossibilidades - de perpetrar uma ação terapêutica com a agilidade que as rotinas do NASF determinam. Destarte, quando o estagiário se insere nessa trama relacional e institucional carregada de 
problemáticas, ele pode assumir, como suas, limitações que são anteriores e exteriores ao seu novo papel de aprendiz, as quais acabam por gerar mais sofrimentos. $\mathrm{O}$ estudante de Psicologia, no momento em que se aproxima do mercado de trabalho, sofre antecipadamente quando vive no seu cotidiano as precariedades do SUS. O Conselho Federal de Psicologia/CFP (2011, pp.14-15) presta auxílio à construção desse argumento:

Garantir a implementação e a efetivação do Sistema Único de Saúde perpassa por diversos fatores, muitos deles relacionados à disponibilidade de recursos financeiros. Um dos aspectos que precisa ser objeto de análise é a precarização das relações de trabalho. A escassez de recursos é um dos fatores que por vezes leva a contratações temporárias ou mediante terceirizações. Em grande parte dos casos, ao fim dos contratos, os profissionais acabam desligados do serviço e novo profissional é contratado, sem falar em possíveis paralisações do trabalho ou sobrecarga de outros trabalhadores

Até este momento, procuramos esclarecer a complexa relação que se estabelece no trabalho profissional do psicólogo clínico, como membro atuante em um NASF. Também têm sido discutidas as possíveis colaborações que a formação acadêmica pode prestar, por meio de subsídios teóricos e técnicos oferecidos pela Psicologia clínica, de modo singular para a aquisição e o desenvolvimento de atitudes clínicas do estagiário.

Levando-se em conta as reflexões apresentadas, a atualidade é o tempo da presença da Psicologia na saúde pública e em equipamentos como os NASF. Ela poderia ser simbolizada por um instante da história profissional dos psicólogos - e dos psicólogos clínicos - que não oferece nomes prontos. Romagnoli diz que o campo da saúde pública é "atravessado por fluxos diversos" e incrementa o debate, porque, para ela, esses trânsitos colocam "em associação distintas disciplinas, representações ideológicas e cenários sóciopolíticos. É no cruzamento desses fluxos que surge a necessidade de criação, é na perturbação desses domínios que práticas são inventadas e que a transdisciplinaridade se dá" (2006, p.13).

Como procuramos demonstrar até aqui, psicólogos estão presentes em instituições públicas de saúde/comunitárias há tempos. Contudo, nossa proposição é a de um repensar dessa presença, de modo que a Psicologia clínica não seja vista como secundária nesse contexto, em favor de outras maneiras de intervir, como, por exemplo, as comunitárias e/ou as sociais e/ ou as da saúde, como se o determinante na definição de uma atitude em Psicologia clínica fosse passível de se fragmentar em nomes pertencentes a uma ou outra subárea de atuação do psicólogo. Desse modo, o espaço do NASF parece necessitar menos de defesas de uma parcela da Psicologia contra outra do que de encontros no seu próprio cerne.

Essa discussão precisa ocorrer em detrimento de quaisquer eixos epistemológicos existentes no campo psicológico, apesar de o olhar deste escritor desfrutar de direcionamento clínico, como esperamos ter esclarecido até aqui. Precisamos permitir que os sujeitos em situação de sofrimento psicológico configurem as prioridades das atitudes de cuidado, e não as querelas acadêmicas. Estas, mesmo que potencialmente fecundas, nem sempre se alinham às necessidades da população. 


\section{Estágio supervisionado e expectativas diante do mercado de trabalho}

Como supervisor de estágio em processos clínicos que se desenvolvem em NASF, temos integrado situações vividas por estagiários dos últimos semestres da graduação. Elas têm se mostrado tão provocantes em intensidade emocional que o desejo do estudante de abandonar essa vertente de atuação profissional se mostra alternativa cotidiana em suas ações e discursos.

A prática de estágios tem indicado ser elevado o custo emocional para o estudante, e isso é mais visível quando esse personagem atua com base no frágil e maniqueísta polo da onipotência-impotência. Aqui cabe retomar argumentos apresentados anteriormente e dizer que as experiências estudantis não são compreensíveis somente a partir do aspecto subjetivo. Elas também se referem às questões institucionais de formação dos psicólogos (Romagnoli, 2006), porém esse é o polo de argumentos escolhido para ser abordado, neste subitem.

A entrada de estagiários, nos NASF já descritos, tem sido marcada pelo desejo onipotente de modificar a realidade da saúde pública por completo, o que invariavelmente redunda em choque contra a impotência. Em meio a esse tipo de anseio estudantil, temos tentado buscar alternativas frente aos extremos, de modo que as forças de trabalho possam instalar-se em lugares intermediários, portanto, mais flexíveis, ao longo do percurso de ensino e de aprendizagem que envolve estudantes e professores.

No prolongamento desse debate sobre as potências dos estudantes de Psicologia clínica, retomamos para ponderações, embora neste instante de modo breve, o tópico sobre as condições de trabalho dos psicólogos na saúde pública. Nesse âmbito, o CFP (2011) recomenda a contratação dos profissionais mediante a realização de concurso público, porque vê nisso um modo de o investimento inicial neles realizado ser mais bem aproveitado, porque suas permanências no equipamento de saúde seriam caracterizadas como de longo prazo. A qualidade da atuação profissional seria de algum modo resguardada, essencialmente porque demissões compulsórias não poderiam ocorrer e porque a comunidade junto à qual ele opera o reconheceria como uma referência estável a quem recorrer, para obtenção da ajuda necessitada.

Em linha semelhante de preocupações, o Ministério da Saúde (s.d.) tem se ocupado do tema precarização das relações de trabalho no SUS, e formaliza o DesprecarizaSUS no final dos anos 2000. No site do MS, encontramos a seguinte constatação: “o trabalho precário em saúde tem sido identificado como um obstáculo para o desenvolvimento do sistema público de saúde. Essa questão compromete a relação dos trabalhadores com o sistema e prejudica a qualidade e a continuidade dos serviços essenciais prestados pelo SUS".

Por meio desses últimos argumentos, de duas organizações que conduzem políticas de educação e de saúde no País, procuramos ilustrar que os discursos sobre os limites do SUS, e em consequência, dos NASF, são realidade concreta. O estagiário tem consciência dessas fronteiras, bem como sobre a sua atuação no NASF ser circunscrita pelo tempo da graduação. Entretanto, mesmo assim deseja prolongá-lo, tornando-se um 
profissional do NASF - desde que não tenha abandonado o estágio, quando da vivência das angústias de impotência anteriormente discutidas, é claro. O concurso público recomendado pelo CFP seria a alternativa para ele buscar vínculo com uma opção laboral mais potente, em um futuro que seria considerado promissor. O estudante sabe, por experiências tidas no campo de estágio, que as dificuldades serão abundantes e inexauríveis, mas também sonha com uma eventual independência financeira e com o desenvolvimento de habilidades e competências como novo profissional, e não mais como estagiário.

E, nesse ponto, o supervisor direto, aquele que abriu as portas para dialogar com a Universidade e que também está sujeito às precarizações das relações de trabalho nos domínios do SUS, se concursado, poderia exercer suas funções com mais amparo nas potencialidades de sua profissão. A sua relação com o estagiário alcançaria grandes benefícios, porque haveria claras distinções entre ambos, o que, no atual momento, não parece existir em Municípios que somente têm podido realizar contratações temporárias de psicólogos, como ocorre no caso em estudo. Do modo como a situação se desenha, assim, psicólogo e estagiário avizinham-se em uma complexa partilha de angústias, que, por sua vez, implica desamparos, o primeiro, pela instabilidade que vive no fazer profissional, e o segundo, pela ruptura prestes a ocorrer com o universo acadêmico.

As fragilidades do sistema de saúde brasileiro não poderiam ser respondidas pelo psicólogo, de modo isolado em relação aos demais profissionais da área da saúde mental e nem desconsiderando o contexto geral da saúde pública que procuramos debater. Pelas características da profissão que decorrem da especialização de olhar sobre os modos de produção subjetiva, temos observado que o profissional da área psicológica, especialmente o estagiário, acaba por absorver em demasia as fagulhas que se desprendem das relações humanas ocorridas no NASF. Precisamos atentar para o fato de que desgastes profissionais e emocionais são muito superiores ao que a clientela ofereceria por si: eles são mais abrangentes porque potencializados pela precariedade estrutural do SUS.

\section{Considerações finais}

Os questionamentos e as reflexões traçados são produto do trabalho de um psicólogo clínico, supervisor de estágios ocorridos no NASF de uma cidade do interior do Centro-Oeste, afiliado a uma IES pública federal. As atividades desenvolvidas têm sido marcadas por esperanças e vislumbres de que a Psicologia clínica marque presença nesse espaço, para que os sofrimentos humanos ali apresentados possam ser, no mínimo, amenizados.

Dois fatores indicam que os registros descritos podem abarcar o cotidiano, a realidade e as angústias de outros formadores de psicólogos clínicos e estudantes comprometidos com a filosofia do SUS. O primeiro refere-se ao trânsito propiciado por autores que produziram ou têm produzido artigos sobre a inserção da Psicologia na saúde pública, alguns dos quais citados no texto.

O segundo fator se pauta em experiências pessoais de leitura, avaliação e construção de projetos pedagógicos de cursos de Psicologia, que realizamos como professor. É possível dizermos que tem havido iniciativas concretas para fazer frente à necessidade 
de afinar discursos dissonantes focados na saúde mental das comunidades. Contudo, inventarmos e pensarmos sobre uma clínica de promoção de saúde permanece como tarefa desafiadora, e o espaço universitário mostra-se potencialmente inventivo nesse sentido, não obstante precise se repensar de modo inesgotável.

O papel do supervisor indireto foi frisado como basilar na formação profissional do psicólogo, para além de uma função idealizada para settings herdados da prática privada, todavia também interessado no que pode haver de utilidade nisso, para compreender os fenômenos humanos apresentados pela realidade da atenção primária à saúde. Ancorado nos moldes oferecidos pela Psicologia clínica, esse personagem permanece requerido não somente para prover recursos teóricotécnicos mas também para promover saúde mental ao estagiário.

E tocar no papel do supervisor indireto é fazê-lo quanto ao papel social dos serviços-escola de Psicologia, que atendem, assim, os compromissos universitários nos quesitos extensão e ensino. O terceiro eixo condutor da Universidade, a pesquisa, não pôde ser ponderado aqui, no entanto, é indiscutível que os NASF também favoreçam investigações diversas, inclusive para que interroguem a si próprios sobre seu funcionamento e sobre a qualidade dos serviços ofertados à população.

O papel do supervisor direto foi, por opção, menos enfocado neste momento. Também para ele, seja contratado ou concursado, atividades de supervisão são necessárias para a articulação da teoria/prática na sua árdua inserção laboral na saúde pública. Porém, indagamos: há condições laborais e financeiras para que esse tipo de exercício seja efetivado na sua rotina? Se ponderarmos o grau de exaustão vivido ao término de um dia de trabalho e o padrão de remuneração praticado na realidade da saúde pública, a resposta encerra-se em uma negativa. Com ela, percebemos anseios de que o mundo acadêmico proporcione graus de ajuda, para suscitar contrapontos diante da realidade vivida nos NASF.

Todos os que se encontram no NASF têm estudado e vivido a Psicologia clínica em tempos e de modos distintos, a despeito de nem sempre terem condições equânimes para refletirem sobre isso. Os custos emocionais mostram-se elevados aos psicólogos e, talvez mais fortemente, ao estagiário de processos clínicos, de modo particular quando, no desempenho de seus diferentes papeis profissionais, veem-se acabrunhados por realidades sociais, políticas e econômicas incontornáveis do ponto de vista individual.

Retomando a contribuição de Romagnoli, tratar questões que evidenciam a formação dos psicólogos para atuar na área de saúde pública é um modo que se tem para explorar o que o distancia de uma verdadeira atuação transformadora. Caso contrário, o desinteresse, a desmotivação e o sentimento de incapacidade e impotência diante dos desafios apresentados por esse modelo de atenção à saúde serão revigorados e perpetuados na sua própria prática. Pelos estagiários e pelos supervisores. Por todos os estudantes de Psicologia clínica. 


\section{Tales Vilela Santeiro}

Doutor em Psicologia como Profissão e Ciência. Professor Adjunto do Curso de Psicologia da Universidade Federal de Goiás, Campus de Jataí, Jataí - GO - Brasil.

E-mail: talessanteiro@hotmail.com

\section{Endereço para envio de correspondência:}

Rua Ana Dias, n.279, Praça José Peres de Assis, Setor Hermosa, Jataí, Goiás, CEP: 75803-320.

Recebido 12/09/2011, 1a Reformulação 09/10/2012, Aprovado 15/10//2012. 


\section{Referências}

Amaral, M. S., Gonçalves, C. H., \& Serpa, M. G. (2012). Psicologia comunitária e a saúde pública: relato de experiência da prática psi em uma Unidade de Saúde da Família. Psicologia: Ciência e Profissão, 32(2), 484-495.

Andrade, L. M. B. de, Quandt, F. L., Campos, D. A. de, Delziovo, C. R., Coelho, E. B. S., \& Moretti-Pires, R. O.. (2012). Análise da implantação dos Núcleos de Apoio à Saúde da Família no interior de Santa Catarina. Saúde \& Transformação Social, 3(1), 18-31.

Conselho Federal de Psicologia. (2009). A prática da psicologia e o Núcleo de Apoio à Saúde da Família. Brasília, DF: Autor.

Conselho Federal de Psicologia. (2011). Senhoras e senhores gestores da saúde, como a psicologia pode contribuir para o avanço do SUS. Brasília, DF: autor.

Costa, L. F., \& Brandão, S. N. (2005). Abordagem clínica no contexto comunitário: uma abordagem integradora. Psicologia \& Sociedade, 17(2), 33-41.

Dimenstein, M. (1998). O psicólogo nas Unidades Básicas de Saúde: desafios para a formação e atuação profissionais Estudos de Psicologia, 3(1), 53-81.

Ferreira Neto, J. L. (2008). Práticas transversalizadas da clínica em saúde mental. Psicologia: Reflexão e Crítica, 21(1), 110-118.

Galvan, G. B. (2007). Equipes de saúde: o desafio da integração disciplinar. Revista da SBPH, 10 (2), 53-61.

Lancetti, A. (2000). SaúdeLoucura: saúde mental e saúde da família (2a ed. aum.). São Paulo: HUCITEC.

Lancetti, A. (2011). Clínica peripatética (6 $6^{\underline{a}}$ ed.). São Paulo: HUCITEC.

Lima, M. (2005). Atuação psicológica coletiva: uma trajetória profissional em Unidade Básica de Saúde. Psicologia em Estudo, 10(3), 431-440.

Lipp, M. E. N., \& Yoshida, E. M. P. (Orgs.). (2012). Psicoterapias breves nos diferentes estágios evolutivos. São Paulo: Casa do Psicólogo.

Lisboa, A. V., Santos, A. L., Bassoli, F. A., Paiva, N. D., \& Fernandes, T. C. (2011). Escuta de famílias em domicílio: ação do psicólogo na Estratégia de Saúde. Psicologia: Ciência e Profissão, 31(4), 748-761.

Ministério da Educação. (2011). Diretrizes Curriculares Nacionais para os Cursos de Graduação em Psicologia: Resolução n.5, de 15 de março de 2011. Brasília, DF: Conselho Nacional de Educação/Câmara de Educação Superior. Recuperado em 20 maio, 2011 dehttp://abepsi.org.br/site/wp-content/ uploads/2010/12/resolucaocneces338.2009.pdf.

Ministério da Saúde. (s.d). Secretaria de Gestão do Trabalho e da Educação na Saúde. Disponível em http://portal.saude.gov.br/ portal/saude/profissional/area.cfm?id_area $=1285$ Recuperado em 19 ago., de 2011.

Ministério da Saúde. (2009). Diretrizes do Núcleo de Apoio à Saúde da Família. Secretaria de Atenção à Saúde; Departamento de Atenção Básica; Saúde na escola / Ministério da Saúde, Secretaria de Atenção à Saúde, Departamento de Atenção Básica - Brasília , DF: Ministério da Saúde (Série B. Textos Básicos de Saúde, Cadernos de Atenção Básica, n.27)

Moreira, J. O., Romagnoli, R. C., \& Neves, E. O. (2007). O surgimento da clínica psicológica: da prática curativa aos dispositivos de promoção da saúde. Psicologia: Ciência \& Profissão, 27(4), 608-621.

Nasciutti, J. C. R. (1996). A instituição como via de acesso à comunidade. In R. H. F. Campos (Org.). Psicologia social comunitária: da solidariedade à autonomia (pp.100-126). Petrópolis, RJ: Vozes.

Nepomuceno, L. B., \& Brandão, I. R. (2011). Psicólogos na Estratégia Saúde da Família: caminhos percorridos e desafios a superar. Psicologia: Ciência e Profissão, 31(4), 762-777.

Neumann, A. P., Cardoso, C., \& Oliveira, S. (2011). Experiência da psicologia na Estratégia Saúde da Família. Psicologia: Ciência e Profissão, 31(4), 868-879.

Nunan, B. A. (2009). NASF: concepções e desafios. In Conselho Federal de Psicologia, A prática da psicologia e o Núcleo de Apoio à Saúde da Família (pp.19-29). Brasília, DF: Autor.

Organização Mundial da Saúde. (2001). Relatório Mundial da Saúde. Saúde mental: nova concepção, nova esperança. Edição Portuguesa. Lisboa: Climepsi. (Título do original: The World Health Report 2001. Mental health: New understanding, new hope).

Pombo-de-Barros, C. F., \& Marsden, M. (2008). Reflexões sobre a prática do psicólogo nos serviços de saúde pública. Arquivos Brasileiros de Psicologia, 60(1), 112-123.

Romagnoli, R. C. (2006). A formação dos psicólogos e a saúde pública. Pesquisas e Práticas Psicossociais, 1(2), 1-15. Recuperado em 10 ago., 2012 de Recuperado em 10 ago., 2012 de http://www.ufsj.edu.br/portal-repositorio/File/ revistalapip/RobertaRomagnoli.pdf.

Simon, R. (1981). Formação do psicoterapeuta para a realidade brasileira. Boletim de Psicologia, 33 (81), 67-73.

Sousa, V. D., \& Cury, V. E. (2009). Psicologia e Atenção Básica: vivências de estagiários na Estratégia de Saúde da Família. Ciência \& Saúde Coletiva, 14(1), 1429-1438.

Spink, M. J. P. (Org.). (2006). A psicologia em diálogo com o SUS: prática profissional e produção acadêmica. São Paulo: Casa do Psicólogo.

Sundfeld, A. C. (2010). Clínica ampliada na Atenção Básica e processos de subjetivação: relato de uma experiência. Physis: Revista de Saúde Coletiva, 20(4), 1079-1097.

Yoshida, E. M. P. (1993). A psicoterapia breve na realidade brasileira. Mudanças: psicoterapia e Estudos Psicossociais, 1(1), 23-35.

Yoshida, E. M. P., \& Enéas, M. L. E. (Orgs.). (2007). Psicoterapias psicodinâmicas breves: propostas atuais (2a ed.). Campinas, SP: Alínea. 